Paideusis

\title{
An Objective Aesthetics? Implications for Arts Education
}

\section{Sheryle Bergmann}

Volume 8, Number 1, 1994

URI: https://id.erudit.org/iderudit/1073262ar

DOI: https://doi.org/10.7202/1073262ar

See table of contents

Publisher(s)

Canadian Philosophy of Education Society

\section{ISSN}

0838-4517 (print)

1916-0348 (digital)

Explore this journal

Cite this article

Bergmann, S. (1994). An Objective Aesthetics? Implications for Arts Education. Paideusis, 8(1), 17-29. https://doi.org/10.7202/1073262ar viewed online.

https://apropos.erudit.org/en/users/policy-on-use/ 


\title{
An Objective Aesthetics? Implications for Arts Education
}

\author{
Sheryle Bergmann, University of Manitoba
}

\section{Introduction}

It has been argued that the very idea of education in the arts presupposes that aesthetic judgments are in some sense objective. However, aesthetic judgments are considered by many to be subjective. A discussion of this issue has important implications for arts education. If aesthetic judgments are purely a matter of subjective opinion, one would be hard pressed to justify the inclusion of the arts in the curriculum as an educative activity. Although one may justify the inclusion of the arts on the basis that participation in arts activities allows students an opportunity to explore their personal feelings, one might question the place of these activities in an educational context. I agree with Peters who contends that for an activity to be considered "educational," it must denote some kind of learning which "implies mastering something or coming up to some standard as the result of experience." It is beyond the scope of this paper to explore in more detail what it means to "educate," but I will be working within the understanding that "education" involves this latter kind of learning. An exploration of subjective feelings may have a place in a therapeutic setting, but in an educational context, students must learn to "give form" to their feelings as opposed to simply exploring them. This "giving form" to feelings involves more than subjective opinion. If aesthetic judgments involve more than subjective opinion, it is possible for students to improve their ability to understand and to create works of art and, thus, education in the arts becomes a valid enterprise. Hence, it is of fundamental importance that arts educators explore the issue of whether aesthetic judgments are to some degree objective.

At this point, it is important to clarify what is meant by the terms "subjective" and "objective." It is helpful to view these concepts as two ends of a continuum. At the subjective end, we have judgments based upon ourselves as subjects. That is, such judgments are based upon our personal feelings. Some of them like "I feel sick" are non-debatable, while others such as "I feel that arts courses should be given preferred time slots in the curriculum" display a personal bias. It is the personally biased judgments which are typically utilized as ammunition by those criticizing the arts as being a subjective activity and are considered to be idiosyncratic to particular individuals.

At the other end of the continuum, we have judgments based upon the properties of objects. Traditionally, such judgments were seen to be the domain of the sciences. Scientists would observe "facts" about the universe and make judgments based upon them. However, with the recent work of epistemological theorists and philosophers of science (for example, Kuhn and Feyerabend), it has been demonstrated that there are no such facts. Every observation is "theory-laden" to some degree. That is, how we observe the world is based to a large degree upon the scientific theories which are being adhered to at the time. The different "observations" of the planets prior to and after the Copernican revolution is a good example of the "theory-ladenness" of such observations. 
There are "theory-laden facts" at one end of the continuum and "personal feelings" at the other end. All statements involving feelings about external objects, such as "I feel that arts courses should be given preferred time slots in the curriculum," involve feelings regarding the value of art. By contrast, "I feel sick" statements are non-debatable because there are no objective properties by which one can demonstrate the truth or falsity of such statements. Artistic judgments are often considered to be of the non-debatable type in which one opinion is as valid as another. However, I claim that artistic judgments are debatable, that they are more like the "I feel that arts courses should be given preferred time slots in the curriculum" statement which can be judged against various accounts of the value of art. The position which artistic judgments occupy on the objective-subjective continuum is the topic of the next section.

\section{The Objective-Subjective Continum}

I propose that although aesthetic activity may not fall as far towards the objective end of the objective-subjective continuum as scientific activity, aesthetic activity should not be relegated to the purely subjective end. The notion that there is some middle ground between pure subjectivity and complete objectivity is reiterated by Rader and Jessup:

Subjective value is a property of subjects and objective value is a property of objects; but neither, in isolation, is the entire value. The whole relational complex, I-R-O ["I" is the interest of the subject, " $O$ " is the object of the interest, and " $R$ " is the relation between them], is the only actual and complete value. The two opposing theories-subjectivism and objectivismrepresent partial truths, and the whole truth combines the valid insights of both. ${ }^{2}$

Macdonald also denies a objective-subjective dichotomy when he suggests that 'aesthetic judgment is not a matter of 'either-or,' with pure subjectivity (a chaos of personal opinion) on the one hand, and the complete objectivity claimed by science on the other hand." 3 Macdonald explains the subjective criterion of aesthetic judgments as entailing the pleasure-giving quality of a work of art: "If the individual does not find the work of art, be it a picture, a piece of music, a statue, or a poem, interesting and worth contemplating on its own account, then for him that work is not functioning as art."4 However, the more objective criterion of aesthetic judgments involves, according to Macdonald, the quality of significance or depth of a work of art:

[T] he measure in which. . [the artist's] work possesses the quality of significance yields a standard, and by no means a purely personal standard, for assessing the value of his product. This means in effect that the 'public' test is applicable, though not of course with the clarity and finality attaching to it in the sphere of science. 5

Macdonald adds the caveat that his "public" test does not involve the "clarity and finality" attached to science. By this, I take him to mean that there is something between "a purely personal standard" and scientific standards.

Another attempt to clarify the concept of the objective, and thereby explain how aesthetic judgments can be classified as objective, is made by Meynell. He refers to two senses by which a judgment could be considered 
objective as "A-objective" and "B-objective." Meynell considers a judgment to be A-objective if it is concerned with what is the case about objects apart from their actual or potential effects on human beings. He considers a judgment to be B-objective if it can be more or less verified or falsified in the experience of conscious subjects. Meynell suggests that typical scientific judgments are both A-objective and B-objective: "that is, they can be more or less verified or falsified in the experience of conscious subjects and they refer to what might have been the case even if such experiences and the subjects enjoying them had never existed." Aesthetic judgments, on the other hand, are certainly not A-objective for "they are about objects in their actual or potential relation to intelligent, sensitive subjects, and not about objects as they might have been even if such subjects had never existed."7 According to Meynell, this distinction between A-objective and B-objective allows for the possibility of aesthetic judgments being both objective and subjective.

It may be inferred from what I have said that there is a sense in which both those who have argued for the objectivity and those who have argued for the subjectivity of aesthetic judgments are correct; the former in asserting their B-objectivity, the later in denying their A-objectivity. Aesthetic judgments are "subjective" in that their validation is entirely a matter of the actual or potential effect of the things concerned on the satisfaction of human subjects; they are "objective" in that they can thus be shown to be true or false, quite independently of the attitude which may happen to be expressed by those who make them in the making of them. ${ }^{8}$

Can aesthetic judgments be shown to be true or false to some degree? I answer in the affirmative but this necessitates moving aesthetic judgments nearer to the "objective" end of the subjective-objective continuum. At this end, judgments are based upon the properties of objects-in this case, art objects. These properties would include such aesthetic qualities as line, design, colour, and shape, and the relationship between these, as well as the fittingness of this form to the content being expressed. These qualities are independent of particular persons experiencing works of art. Thus, we have a degree of objectivity. However, the application of this knowledge is intimately tied to the thoughts and feelings of the persons experiencing the art. Thus, there is still a degree of subjectivity. It must be emphasized that the degree of subjectivity is not as extreme as undebatable "I feel sick" statements. As Bailin points out:

Aesthetic judgments do not reduce to personal preferences. Rather, they refer to objective features of works-their aesthetic properties, and to aesthetic principles. Thus, it is possible for there to be assessments of works of art which are unjustified, just as there are unjustified scientific judgments. It is, then, an intimate interplay of rational judgment and sensibility which is operating in the valuing of works of art. ${ }^{9}$

Once people are familiar with aesthetic qualities (they may not necessarily agree upon the importance placed upon any particular quality), they have something with which they can communicate their impressions to others experiencing the same work of art. Thus, if I feel that a particular painting leaves me feeling cold, I can point to the icy blue colours and the sharpness of the brush strokes used to apply those colours. Others may not interpret the painting in this way. In fact, they may say that the image the artist is representing is not one conducive to an interpretation of coldness. However, we are able to utilize talk of 
aesthetic qualities to provide reasons for our interpretations. Another example of this form of reasoning is that of literary criticism. In interpreting works of literature, scholars can argue for different interpretations based on textual evidence. This evidence involves aesthetic elements such as literary design which would include dramatic irony and figurative language. The provision of reasons involving such aesthetic qualities negates the possibility of aesthetic judgments being purely subjective. These reasons utilize a body of knowledge independent of the people applying it. This is where the objectivity lies.

The suggestion that aesthetic judgments are in some sense objective because of the nature of the reasons given for one's interpretation has not gone uncontested. Ducasse questions the nature of such reasons:

But of what nature are those reasons? They are, ultimately, of the same nature as would be that offered by a man arguing that my pen had to fall when I let go of it a moment ago because of gravitation. Gravitation is but the name we give to the general fact that unsupported objects do fall, and at a certain rate; but it is not a reason, or cause, or proof of that fact. To say that something always happens is not to give any reason why it ever does. Therefore, when I say that a certain design is ugly because it is against the "law of symmetry," I am not giving a reason why it had to give me aesthetic displeasure, but only mentioning the fact that it resembles in a stated respect certain others which as a bare matter of fact also do displease me. This character which displeases me and many persons may, however, please others. And, what is more directly to the point, it not only may but it does,--jazzy or uncouth though I may call the taste of such persons. ${ }^{10}$

The key to responding to Ducasse's objection lies in his use of the concept of "taste." Ducasse has failed to distinguish between the pleasure or lack of pleasure which persons experience-that is, a reflection of their taste, with the reasons which they offer for a particular interpretation of a work of art. This distinction is exemplified in the situation where two people agree on an interpretation of a work of art and where they even provide similar reasons for their views. However, one person may like the work while the other dislikes it. Thus, liking a work of art is distinct from approving of it in an aesthetic sense. This distinction between what I would call taste and judgment is reiterated by Morawski. He defines "taste" as "a certain disposition and the actual experiences connected with it, which are not identical with aesthetic judgment. This disposition belongs to the sensibilities and the imagination, which produce a specific and immediate response to some objects or qualities in a context which might be termed 'aesthetic'."11

Morawski does not consider a taste response to be of an intellectual character. He explains such responses as being rooted in our natural dispositions as well as in our cultural evolution. However we are to account for our taste response, it is sufficient for our purposes to note the distinction between such a response and a response which is less immediate and which can be considered to be somewhat more objective. Morawski refers to such a response as one of aesthetic judgment:

Aesthetic judgment proper is more remote from the taste experience, since it invokes some objective reasons to justify why "I like this" or, to restate it, why " $\mathrm{X}$ is likeable." In this instanoe, thought processes are intensified and the initial existential propositions to the effect that such are my feelings or 
that such are my sentiments towards the given object yield to implicational utterances or even to comparative formulas describing my experiences as compared with the feelings of others or describing the qualities or objects actually experienced as compared with those experienced on other occasions. In each of these latter cases, aesthetic judgment is an appraisal, that is, a statement ascribing for certain reasons some values to the experience, to its objective counterpart, to the adequate relation between them, or to some context in which such a relation might appear. ${ }^{12}$

In making this distinction between taste and aesthetic judgment, Morawski is able to deal with the issue of objectivity. He rephrases his distinction as being one "between universality based only on shared tastes and opinions (which in my scheme does not go beyond relativism) and universality that has its foundation in the relational equivalence of subjective and objective conditions (traits) observed in the aesthetic process." 13 Thus, we come full circle to the proposition that aesthetic judgments involve a relationship between subjective and objective conditions. In the next section, I will explore further the objective conditions in the aesthetic process.

\section{Objective Conditions}

An activity such as dance or an object such as a painting are typically considered to be perceptually interesting and attractive if they involve certain qualities. It must be emphasized that it is the aesthetic qualities which bestow a degree of objectivity on artistic activity rather than that such activity is typically considered to be perceptually interesting. I am not claiming a collective subjectivity for artistic judgments. Although it may be suggested that common collective feelings about art lend a degree of objectivity to such activity, I would disagree. It is not the common feelings about art but rather the common understanding of artistic properties which bestow a certain degree of objectivity to artistic activity. It is an understanding of aesthetic qualities which distinguish art from other subject areas. Richmond illuminates this point in his discussion of the educational value of the arts:

.. .if art is to be differentiated from purely conceptual matters, from the pragmatic communication of information in images, or from social studies, for example, then it must surely be by some reference to aesthetic intentions and qualities, i.e., to such things as style, character, design, skilful use of materials, originality, expressiveness, and the fittingness of form with content. ${ }^{14}$

The suggestion that some aesthetic qualities are common to many art forms is one which has been contested. Sheppard states that "if we try to develop such an extension in detail, we are immediately confronted by the problem that formal features in the different arts seem at first to be of very different kinds." 15 However, Sheppard notes that, in considering formal features of a work of art, we are considering relationships between features: "In discussing painting we talk not just about the shapes and colours used but about the balance and the symmetry of the composition, that is, about the relationships between the shapes and colours."16 It is talk of such relationships which transcends different art forms. For example, the qualities of balance and symmetry can be experienced in a creative dance piece. A dance might be created which has an even number 
of dancers performing symmetrical movements on opposing sides of the stage. Likewise, a dance could convey imbalance and asymmetry by utilizing an odd number of dancers performing movements at various levels with varying degrees of intensity. It is the utilization of "aesthetic qualities" talk such as reference to balance and symmetry which makes it possible to compare and contrast works of art in the same as well as different art forms.

Although aesthetic qualities may transcend different art forms, some qualities play a more prominent role in particular art forms. Meynell suggests that "visual art excels in its clarification of sensation; that music excels in the depiction of mood; that literature is unique in its capacity to anatomise judgment and decision."17 Meynell goes into more detail in comparing and contrasting different ant forms by first suggesting qualities common to all art forms and, then, considering how the emphasis varies according to the specific art form under discussion:

Each type of art is a matter of manipulation of a medium (a) to provide a structure (b) which is a means to satisfaction through exercise and enlargement of consciousness. While representation is certainly not the only means by which such an end may be secured, it is at least characteristic of literature and the visual arts that they exercise and enlarge consciousness through representation (c); and that such representation is more deeply satisfying when it involves some kind of reference to what is of central importance in human life (d). ${ }^{18}$

Regarding the specific artistic forms of literature, Meynell specifies the qualities deemed to be valuable:

When examining the criticism of novels, plays, and other works of literature, such works are deemed to be of value in proportion to (i) their illustration and demonstration of what is of central importance for human life; (ii) the originality of their use of language and their treatment of plot, character, situation, and so on; (iii) their just representation of people, things, and circumstances; and (iv) their overall unity in variety of substance and effect. It will be seen that these features correspond respectively to (d), (a), (c), and (b) above. 19

Regarding works of visual art, Meynell suggests they "are found to be of value in proportion to (as well, presumably, as their exploitation of their medium as such) (i) their enhancement of perception and imagination (often through representation); (ii) their emotional significance; (iii) their unity in varietywhich correspond to (c), (d), and (b)."20 Finally, regarding works of music, he claims their value "is found to be a matter of (i) its exploitation of the medium of sound as such; (ii) the clarity and intensity of its depiction of emotion and mood; (iii) its unity in variety-which correspond to (a), (d), and (b).,"21

Meynell considers the art forms of literature, visual art, and music. Dimondstein performs a similar analysis but includes creative dance:

Each art form has its own distinguishing characteristics, provides a unique image, and uses particular media. How, then, can we give the arts a sense of unity as well as recognize their distinctiveness? To do so is to consider them in their broadest context, as parameters of space-time-force through which the functions of the arts are expressed. As parameters, they may have various values, yet each in its own way is necessary in creating and determining the aesthetic effects of any particular form. They cannot, then, be 
conceived as technical elements, but as the connective tissue underlying the expression of ideas and feelings. 22

Dimondstein give examples of how the same quality is expressed in different art forms: "When we speak of an energetic line or a strong colour relationship in painting, of tension between the volumes or contours in a sculpture, of the power of a movement in dance or the intensity of an image in poetry, we are expressing a sense of vitality." ${ }^{23}$ Of course, not everyone may agree that a work of art (or even an entire art form) exhibits a particular quality. However, I am suggesting that the independent body of knowledge involving these qualities not only bestows a certain degree of objectivity upon aesthetic judgments, it also makes it possible to engage in the process of providing reasons for one's interpretation of a work of art in order to change another's interpretation. Thus, we return to a discussion concerning the reasons given for aesthetic judgments.

\section{Subjective Reasoning?}

The charge of subjectivism is typically levied against the arts as a result of comparing the arts to science-once thought to be the paradigm of rationality. Best notes this situation when he states that "for what often impels people to subjectivism about the arts is the common assumption that the sciences are paradigm examples of rationality, coupled with the recognition that artistic judgments are obviously not open to scientific verification."24 However, this comparison simply demonstrates that art is not science. Just because artistic judgments are not open to the forms of verification utilized in the sciences, it does not follow that they are closed to all forms of verification. More flexible forms of verification involve an exploration of different kinds of reasoning. Besides the deductive and inductive reasoning which are characteristic of mathematics and science, reasoning can also be used to give an interpretation or picture of a phenomenon or situation. Best cites Wittgenstein's duck-rabbit figure to illustrate how reasons can be given to support one's interpretation: 'See, it's a rabbit-here are its ears." However, Best aptly notes that "there is not the arbitrary unlimited possibility implied by subjectivism. The figure cannot be seen as a clock, for instance." 25 Best's comments concerning the limitations imposed on this sort of reasoning are important to keep in mind. Too often, aesthetic judgments are perceived as "anything goes"-that is, whatever a person subjectively thinks or feels about a work of art is correct. However, aesthetic qualities, such as the fittingness of form to content, provide a conceptual framework within which aesthetic judgments are given something of an objective basis.

It must be emphasized that aesthetic qualities are not "created" by individuals. As Hepburn points out:

we do not create and project the aesthelically relevant properties; rather, our perceptual apparatus gives us the sensitivity to discriminate and apprehend them as features of the life-world. The fact that these do not show themselves when we explore reality in the objective manner by the methods of science, tells us not that they must be the product of our 'projection', but only that those are not the methods and instruments which reveal them. ${ }^{26}$

Best reiterates the importance of the conceptual framework which is 
shared by those apprehending aesthetic qualities. He suggests that "to decline to accept an interpretation of a novel or play for which the textual evidence is overwhelming and in the absence of countervailing reasons is a manifestation not of unfettered individuality but of a failure to understand the work and the relevant concept of art." 27 Individuality should not preclude the answerability to reason.

On the contrary, independent thinking in the arts as much as in science, mathematics, and philosophy is not only compatible with but presupposes rationality. What is required is not conformity but that independent thought should be answerable to valid reasons. In that sense, rationality is a precondition of the individual differences in the creation and appreciation of the arts which are such significant expressions of the rich diversity in human personality. It is a fundamental misconception about this issue which is a major source of subjectivism. ${ }^{28}$

In suggesting that individual thought is answerable to reason, I am not claiming that everyone will agree upon one interpretation of a work of art. As Best puts it: "It follows from the meaning of 'interpretation' that disagreement is possible, and disagreement makes sense only by reference, if only implicit, to a shared conception."29 I am suggesting that an understanding of aesthetic qualities are identified by the "shared conceptions" which make it possible to provide reasons for the interpretation of a work of art. People may not agree on an interpretation but that, having acquired some knowledge of aesthetic qualities, they can convey their interpretations in such a way that others, although they may not agree, can at least understand the reasons for the interpretation. The reasons given for the interpretation are based on the utilization of aesthetic qualities which I have argued are objective in the sense that they are part of a body of knowledge independent of the persons utilizing them. An understanding of these qualities, as well as the utilization of them in the reasoning process, can be fostered through educational means. Thus, we turn now to an exploration of the implications of the preceding discussion for arts education.

\section{Educational Implications}

An expansion of the notion of reasoning to include reasons appropriate for a particular interpretation of a work of art has positive implications for the justification of arts education. Arts education not only bas a place in the "realm of the rational" but it also provides a situation where students can attain more comprehensive forms of reasoning than that achieved in an educational system which does not include aesthetic activity. That is, if providing reasons for an interpretation of a work of art is a form of reasoning of central importance to the arts (I am not suggesting that it is used exclusively in the arts-scientific theorizing also involves such reasoning), it is to the detriment of the student not to be allowed the opportunity to experience such reasoning.

Beyond adding to the argument for the inclusion of arts education in the educational curriculum, the preceding discussion has the practical implication of providing content for an arts education curriculum. If the objective conditions of aesthetic judgments rely on the body of knowledge involving aesthetic qualities, it is incumbent upon the arts education teachers to help foster an understanding of these qualities in their students. The subjective conditions 
involving the students' feelings toward a piece of art may not be something conducive to an educational process, but the reasons they give for these feelings may be. That is, if students can be given "tools" to be used in interpreting works of art, they may come to a better understanding of what is being expressed through the art. This understanding will have an affective component to it, but this affective component enhances rather than detracts from the understanding gained through artistic activity. As Hepburn points out:

\begin{abstract}
The perspective-variability of the subjective need not be seen as defect-as a falling-short of a (dubiously coherent) 'absolute' view. It is the source, and not only for a Leibnizian monadology, of a limitlessly diversified set of worlds-as-experienced, individual, but-with the crucial help of the arts-in a measure communicable, and not at all to be thought of as the solipsistic inner imaginings of 'windowless' subjects. ${ }^{30}$
\end{abstract}

To understand human experience as communicated through the arts should be a priority of arts educators and, thus, it is incumbent upon teachers to help students develop knowledge of aesthetic qualities along with the ability to provide interpretive reasons for what they experience through artistic activity. To conceive of a work of art critically and to convince others of what they consider to be the most adequate interpretation of an art piece are intellectual achievements which are necessary for students if they are to gain understanding through the arts.

It must be emphasized that it is not only art interpretation and art theory which require an understanding of "objective" aesthetic qualities. An understanding of aesthetic qualities is also important for art production. Aesthetic qualities act as standards to enable us to distinguish between the valuable and the non-valuable work of art. Maitland gives an example of an artist making changes to a painting: "[I]f he were articulate and willing, he would point to certain features of the paintings and explain why certain choices did not work and why the changes were better in relation to the emerging works of art and what he wants to achieve." 31 An example from a creative dance class may further elucidate the role of aesthetic qualities in fostering understanding. If students were asked to create a dance based on a piece of music, the results would be quite different if the task were given within the constraints of acknowledging aesthetic qualities as opposed to creating "free-form" with no aesthetic requirements. In acknowledging aesthetic qualities, the students would have to listen carefully to the music. Qualities of the music would have to be acknowledged (changes in tempo, changes in volume). Movements could then be performed which coincided with the qualities of the music (fast movements with fast music), or movements could be utilized which created a feeling of dissonance with the qualities in the music (light movements to heavy music). Working within the constraints of aesthetic qualities, however, helps foster the understanding of both the aesthetic qualities of music and movement, for example, and of the feelings which can be created utilizing such qualities (the feeling of dissonance created by juxtaposing contrasting qualities). I am suggesting that this understanding would not be developed if students simply turned on some music and moved to it. Abbs defines the aesthetic as "a mode of apprehending through the senses the patterned import of human experience." "32 It is giving the experience with the music a "patterned import" wherein lies the 
possibility of an aesthetic experience and the possibility of attaining a rich understanding.

Knowledge and use of aesthetic qualities are what Collingwood had in mind when he spoke of artists "knowing what they were doing."4 Once again, this knowledge of aesthetic qualities is necessary for expressing thoughts and feelings through artistic expression if this expression is to foster a greater understanding of the thoughts and feelings being expressed. I propose that knowledge of such aesthetic qualities can be acquired through the appreciation of great works of art. Thus, there is an important connection between appreciating and creating art. I must emphasize that in appreciating works of art, these works should not be limited to one art form. As argued previously, aesthetic qualities transcend different art forms. Thus, appreciating the imbalance in a visual work or the disharmony in a musical piece may help a dancer to understand the possibility of expressing imbalance through movement.

In conclusion, developing an understanding of aesthetic qualities is important for both art appreciation and art production. It might be easier to develop an initial understanding of aesthetic qualities through art interpretation and art theory. However, this understanding should be transferred into art production as soon as possible. Unfortunately, a focus on aesthetic qualities is frequently viewed as impinging upon children's "free expression" through art. However, I am arguing that an understanding of aesthetic qualities is a necessary condition for the creation of aesthetically valuable art. This approach would have implications not only for the selection of lesson content but also for the possibility of evaluating students' achievements. The content selected for art lessons would involve activities geared toward developing an understanding of aesthetic qualities-for example, observing the symmetry in a painting and then creating such symmetry in a dance piece. It would then become possible to evaluate the students' achievement by observing whether the dancers were able to express the concept of symmetry through movement. Such activity may be criticized as being too intellectual and devoid of feeling. However, this should not be the case. Although I have been arguing that artistic activity should occupy a position closer to the "objective" end of the subjective-objective continuum than the "subjective" position it is typically perceived to occupy, art is still experienced by subjects and this degree of "subjectivity" should be shared with the students. McAdoo argues that,

effective arts teachers display a capacity not only to articulate the theme of the work but, in so doing, to reproduce in their pupils' imaginations something of the living experience that they themselves must have had of the work-sometimes, but not necessarily, as a result of reproducing it again in themselves, for they may rely simply on their memory of an earlier experience. 5

The goal of the arts education program, then, is to help students experience the arts from the perspective of human subjects, yet still not lose sight of the objective qualities of the arts-that is, aesthetic qualities, for it is these qualities that make arts education possible. 
${ }^{1}$ R. S. Peters, "Democratic Values and Educational Aims," Teachers College Record, 80(3), 1979, 465.

${ }^{2} \mathrm{M}$. Rader and B. Jessup, Art and Human Value (Englewood Cliffs, New Jersey: Prentice-Hall, Inc., 1976), 15.

3J. Macdonald, A Philosophy of Education (Toronto: W.J. Gage Ltd., 1965), 43.

${ }^{4}$ Ibid., 43.

$5_{\text {Ibid., }} 46$.

${ }^{6} \mathrm{H}$. Meynell, The Nature of Aesthetic Value (Albany: State University of New York Press, 1986), 8.

${ }^{7}$ Ibid., 8.

8 Ibid., 10.

${ }^{9} \mathrm{~S}$. Bailin, Achieving Extraordinary Ends: An Essay on Creativity (Dordrecht: Kluwer Academic Publishers, 1988), 55.

${ }^{10}$ C. Ducasse, "The Subjectivity of Aesthetic Value," in J. Hospers (Ed.), Introductory Readings in Aesthetics (New York: The Free Press, 1969), 297-298.

${ }^{11} \mathrm{~S}$. Morawski, Inquiries into the Fundamentals of Aesthetics (Cambridge, Massachusetts: The MIT Press, 1974), 161.

12Ibid., 163-164.

13 Ibid., 174.

${ }^{14} \mathrm{~S}$. Richmond, "Three Assumptions that Influence Art Education: A Description and a Critique," Journal of Aesthetic Education, 25(2), 1991, 5.

${ }^{5}$ A. Sheppard, Aesthetics: An Introduction to the Philosophy of Art (Oxford: Oxford University Press, 1987), 50.

${ }^{16}$ Ibid., 50.

${ }^{17}$ Meynell, The Nature of Aesthetic Experience, 29.

18 Ibid., 45.

${ }^{19}$ Ibid.

${ }^{20}$ Ibid.

21 Ibid., 45-46.

${ }^{22} \mathrm{G}$. Dimondstein, Exploring the Arts with Children (New York: Macmillan Publishing Co., 1974), 30-31.

${ }^{23}$ Ibid., 32.

${ }^{24}$ D. Best, Feeling and Reason in the Arts (London: Allen \& Unwin, 1985), 15.

${ }^{25}$ Ibid., 19.

${ }^{26} \mathrm{R}$. Hepburn, "Art, Truth and the Education of Subjectivity," Journal of Philosophy of Education, 24 (2), 1990, 192.

${ }^{27}$ Best, Feeling and Reason in the Arts, 47.

${ }^{28}$ Ibid., 62.

${ }^{29}$ Ibid., 47.

${ }^{30}$ Hepburn, "Art, Truth and the Education of Subjectivity," 195.

31 J. Maitland, "Creativity," Journal of Aesthetics and Art Criticism, 34, (Summer)1976, 397.

32P. Abbs (Ed.), The Symbolic Order: A Contemporary Reader on the Arts Debate (London: Falmer Press, 1989), 1. 
${ }^{33} \mathrm{R}$. Collingwood, The Principles of Art (Oxford: The Clarendon Press, 1938), 129.

${ }^{34} \mathrm{~N}$. McAdoo, "Realisation in Aesthetic Education," Journal of Philosophy of Education, 21 (2), 1987, 240. 